\title{
Predictive model of multiple emergency department visits among adults: analysis of the data from the National Survey of Drug Use and Health (NSDUH)
}

\author{
Georgiy Bobashev ${ }^{1^{*}}$, Lauren Warren ${ }^{1}$ and Li-Tzy Wu 2* $^{*}$
}

\begin{abstract}
Background: In this methodological paper, we use a novel, predictive approach to examine how demographics, substance use, mental and other health indicators predict multiple visits $(\geq 3)$ to emergency departments (ED) within a year.

Methods: State-of-the-art predictive methods were used to evaluate predictive ability and factors predicting multiple visits to ED within a year and to identify factors that influenced the strength of the prediction. The analysis used public-use datasets from the 2015-2018 National Surveys on Drug Use and Health (NSDUH), which used the same questionnaire on the variables of interest. Analysis focused on adults aged $\geq 18$ years. Several predictive models (regressions, trees, and random forests) were validated and compared on independent datasets.

Results: Predictive ability on a test set for multiple ED visits ( $\geq 3$ times within a year) measured as the area under the receiver operating characteristic (ROC) reached 0.8 , which is good for a national survey. Models revealed consistency in predictive factors across the 4 survey years. The most influential variables for predicting $\geq 3 \mathrm{ED}$ visits per year were fair/poor self-rated health, being nervous or restless/fidgety, having a lower income, asthma, heart condition/disease, having chronic obstructive pulmonary disease (COPD), nicotine dependence, African-American race, female sex, having diabetes, and being of younger age (18-20).

Conclusions: The findings reveal the need to address behavioral and mental health contributors to ED visits and reinforce the importance of developing integrated care models in primary care settings to improve mental health for medically vulnerable patients. The presented modeling approach can be broadly applied to national and other large surveys.
\end{abstract}

Keywords: Emergency department admission, Predictive model, Random forest, Self-rated health, Mental health

\footnotetext{
* Correspondence: bobashev@rti.org; litzy.wu@duke.edu

${ }^{1}$ RTI International, 3040 Cornwallis Rd., P.O. Box 12194, Research Triangle Park, NC 27709, USA

${ }^{2}$ Department of Psychiatry and Behavioral Sciences and Department of Medicine, Duke University School of Medicine, Box 3903, Durham, NC 27710, USA
}

(c) The Author(s). 2021 Open Access This article is licensed under a Creative Commons Attribution 4.0 International License, which permits use, sharing, adaptation, distribution and reproduction in any medium or format, as long as you give appropriate credit to the original author(s) and the source, provide a link to the Creative Commons licence, and indicate if changes were made. The images or other third party material in this article are included in the article's Creative Commons licence, unless indicated otherwise in a credit line to the material. If material is not included in the article's Creative Commons licence and your intended use is not permitted by statutory regulation or exceeds the permitted use, you will need to obtain permission directly from the copyright holder. To view a copy of this licence, visit http://creativecommons.org/licenses/by/4.0/. The Creative Commons Public Domain Dedication waiver (http://creativecommons.org/publicdomain/zero/1.0/) applies to the data made available in this article, unless otherwise stated in a credit line to the data. 


\section{Background}

Although the emergency department (ED) provides a critical source of acute care, repeated ED visits constitute a major healthcare problem. Treatment received at an ED is considered suboptimal because it is not designed to provide continuity of care: it is very costly, and it contributes to overcrowding and provider/staff shortage $[1,2]$. The cost of an ED visit is about 4 times higher than that of an office-based visit, which has a major impact on a nation's healthcare system [3]. ED overcrowding is a key obstacle to healthcare delivery and places an enormous burden on the U.S. healthcare system [1]. It is important to identify predictors of individuals who are frequent ED users because they consume much more healthcare and represent a high-risk, medically vulnerable patient population [3]. Factors associated with having an inadequate timely access to primary care may be associated with ED use (e.g., lower education or income) [4, 5]. In addition, fair/poor selfrated health and severe or chronic medical conditions, such as diabetes, asthma, and cardiovascular or lung diseases, are associated with frequent ED use [5-7]. Substance use (e.g., overdose, injuries) and mental disorders also contribute to ED visits [7, 8].

Existing epidemiological research often has relied on traditional regression approaches (e.g., logistic regression) to estimate the strength of an association between a given factor and ED use, rather than the predictability of cases based on the knowledge of suspected determinants or risk factors. Perception of an independent variable (or a suspected risk factor) that doubles the outcome chances from 30 to $60 \%$ might differ considerably from the one that doubles the chances from 0.001 to $0.002 \%$. In epidemiological research on association, it is common to find a long list of independent variables associated with an outcome. When a number of factors influence the outcome, it is not always clear if there are there some specific complex subgroups that stand out strongly enough to deserve special attention for target intervention.

Thus, the aims of this paper are to

1. evaluate and compare how well different models predict multiple ED visits,

2. validate the models across years, and

3. identify the most influential factors across multiple models.

We answer these questions by conducting predictive modeling. Predictive models estimate probability of an outcome for individuals with specific characteristics, and a number of models of different complexity can be used for making such predictions [9, 10]. Thus, the balance between complexity, interpretability, and consistency of predictors becomes an additional challenge [9-12]. A validated predictive model should not be taken as a test of a hypothesis or causal argument, but rather as a snapshot of what the population-level data show.

The National Survey on Drug Use and Health (NSDUH) is a valuable resource to study multiple visits to the ED. The large size of the NSDUH sample and the richness in measures (including substance use domains, mental health, self-rated health, medical conditions in the past year) allow us to develop high-quality predictive models. When a model captures the underlying relationships in the data, further increase in complexity would lead to fitting noise or "overfitting." By using multiple years of the NSDUH dataset, we can validate reproducibility by using independent datasets for training, validation, and test purposes thus guarding against overfitting [13]. The approaches used in the study can be applied to other public health conditions.

\section{Methods}

\section{Data source and sample}

Data were from the public-use data file of the 20152018 NSDUH. The NSDUH is an ongoing, crosssectional survey designed to provide national estimates of substance use in the U.S. [14-17]. The target population includes household residents from the 50 states and the District of Columbia (including shelters, rooming houses, and group homes; civilians residing on military bases). Participants are selected by representative multistage probability sample of respondents aged $\geq 12$ years. Weighted response rates for household screening ranged from 73.3 to $79.9 \%$ over the 4 years and interviewing response rates ranged from 63.9 to $68.4 \%$ [14-17]. This study focused on adults aged $\geq 18$ years using public-use de-identified datasets $(N=43,561$ in $2015 ; N=42,625$ in 2016; $\mathrm{N}=42,554$ in 2017; $\mathrm{N}=43,026$ in 2018).

\section{Data collection}

Respondents were interviewed privately at their places of residence. Most sociodemographic questions are administered by interviewers using computer-assisted personal interviewing $(\mathrm{CAPI})^{1}$. Other questions of a sensitive nature (substance use, health status) are administered with audio computer-assisted self-interviewing (ACASI), which provides respondents with a highly confidential means of responding to questions.

\section{Dependent variable}

Any ED use was defined as having one or more ED visits in the previous 12 months ("During the past 12 months,

\footnotetext{
${ }^{1}$ Marital status was changed to ACASI in 2015 then, because of data quality issues, was moved back to CAPI in 2016-2018. Education also was administered with ACASI.
} 
that is, since [DATEFILL], how many different times have you been treated in an emergency room for any reason?"). We focused on multiple ED visits ( $\geq 3$ times/ year) [18].

\section{Potential correlates of ED visits}

Based on Andersen's healthcare utilization model, we examined 46 variables that included predisposing (demographics), enabling (family income, educational level, population density of residence), and need-related (substance use, mental health, medical health, overall health) variables as potential determinants of ED visits $[18,19]$. Thus, the variables selected into the study are not the result of a screening or data mining exercise but rather the result of careful selection based on prior literature and validated analyses.

\section{Sociodemographics}

Respondents' age, sex, race/ethnicity, family income, insurance status, marital status, educational level, and population density of residence were examined as potential correlates of ED use $[18,20]$. Race/ethnicity includes Non-Hispanic white, non-Hispanic African American/ black, non-Hispanic "Other" and Hispanic. The nonHispanic "Other" category includes Native American/Alaska Native, Native Hawaiian/Other Pacific Islander, Asian, and multiple-race.

\section{Past-year substance use}

Tobacco, alcohol, and other nine drug classes were assessed in separate sections, which included a description of the substance class and a list of substances in that class. Tobacco use included use of cigarettes, smokeless tobacco (i.e., snuff, dip, chewing tobacco, or "snus"), cigars, or pipe tobacco ${ }^{2}$. Illicit or nonmedical drug use included marijuana/hashish, cocaine/crack, heroin, hallucinogens, inhalants, prescription opioid pain relievers ${ }^{3}$, prescription stimulants/amphetamines, prescription tranquilizers, and prescription sedatives.

\section{Past-year alcohol or drug use disorders}

Respondents who reported alcohol or drug use in the past year were assessed by a set of structured and substance-specific questions designed to operationalize DSM-IV criteria for abuse of or dependence on each the substance class.

\footnotetext{
${ }^{2}$ Past month pipe tobacco use is used in this measure because past year pipe tobacco use is not available.

${ }^{3}$ Although all the pain reliever subtypes referenced in the NSDUH questionnaire are opioids, respondents could specify that they misused a non-opioid pain reliever (e.g., prescription-strength ibuprofen) [16].
}

\section{Past-month nicotine dependence}

Nicotine dependence was defined as specified by the Nicotine Dependence Syndrome Scale (NDSS) and the Fagerstrom Test of Nicotine Dependence (FTND) [21, 22]. To optimize the number of respondents classified as having current nicotine dependence, NSDUH categorizes respondents as having nicotine dependence in the past month if they meet criteria for dependence as specified either by the NDSS or FTND [23].

\section{Past-year mental health}

Based on prior research on healthcare use, we examined major depressive disorder and anxiety characteristics [19]. Questions assessing major depressive episodes (MDE) were based on DSM-IV criteria [24]. Anxiety indicators utilized were "During the past [time period] (past 30 days or past 12 months, time period that respondent felt their worst emotionally), how often did you feel restless or fidgety?" and "During the past [time period] (past 30 days or past 12 months, time period that respondent felt their worst emotionally), how often did you feel restless or fidgety?"

\section{Medical health}

Medical conditions (asthma, chronic bronchitis, emphysema, or chronic obstructive pulmonary disease (COPD), cirrhosis of the liver, diabetes or sugar diabetes, any kind of heart condition or heart disease, Hepatitis B or C, high blood pressure, HIV/AIDS, cancer/malignancy of the larynx/windpipe or lung, or sexually transmitted disease) were assessed by a series of discrete questions. Asthma was defined for the current time period; sexually transmitted disease and heart conditions were defined for past year; and all other conditions were asked for the respondent's lifetime.

\section{Overall health}

Respondents' self-rated overall health had categories excellent, very good, good, fair, and poor. Fair/Poor health was associated with frequent healthcare use and chronic illness $[6,25,26]$. Following this analysis, we grouped fair, and poor categories to create a dichotomous indicator for self-rated health.

\section{Analysis methods}

\section{Training and validation datasets}

We used two datasets for model building: one for training and one for validation. We included the results from two additional datasets to show how the models performed on earlier data. The training dataset (2017 data) was used to develop a model by performing model building and selection algorithms described below. Candidate models with similar performance on the training set were validated on a separate validation dataset (2018 
data). Finally, the best performing model was rerun on several additional validation datasets from prior years (2015 data and 2016 data). In model selection, we selected the simpler and more interpretable model from similarly performing models (parsimony rule).

\section{Full main effects logistic regression}

The sample size is large enough to incorporate main effects from the entire set of 46 variables. However, the incorporation of all possible interactions is not feasible, and other methodologies should be used to identify potential interactions. Additionally, the predictive value of full regression is often not optimal because of the potential for fitting the noise.

\section{Least Absolute Shrinkage and Selection Operator (LASSO) regression}

LASSO regression methodology penalizes models for overfitting and controls for collinearity. Parameter estimates are generally "shrunk" toward zero, which guards against overfitting and allows for the identification of a robust set of predictors [27]. The estimation of standard errors for LASSO has been under development but there is no clear consensus on their interpretation [28]. This last restriction is not critical because the exact inference of the coefficient values is not an objective here.

\section{Stepwise logistic regression (main effects)}

Stepwise logistic regression was used to identify main effects associated with the outcome with an Akaike Information Criterion (AIC) to control for overfitting [13]. The actual values of the regression coefficient are not the objective, and for predictive purposes, stepwise regression can provide useful insights.

\section{Classification tree}

Possible interactions were estimated from a classification tree. Classification trees recursively partition the sample into groups where subjects within a group are more homogeneous than they are to those in other groups with respect to outcome [11, 13]. A tree model can be summarized in a single categorical variable with categories corresponding to the logical combination of variables defining the terminal nodes. This variable can then be added to a (stepwise) logistic regression to represent most prominent interactions.

\section{Random forests}

Random forests extend classification trees in two dimensions [11]. One dimension is to perform classification trees on each of many (e.g. 200-400) bootstrap samples from the original data. Each tree provides a prediction of individual outcome; thus, for each subject, we obtained an "ensemble" of predictions. The variance of these estimates across the trees characterizes prediction uncertainty. The second dimension is to choose only a random subset of predictors to be used at each sample partitioning. This additional use of randomization allows the model to incorporate useful, but weaker, predictors that otherwise would be masked by stronger predictors.

\section{Variable importance}

Random forests provide a very useful evaluation of the relative variable importance for prediction. The importance analysis is done by randomly resampling (scrambling) one variable at a time. This is equivalent to replacing the variable with noise. Model predictive ability is then evaluated in terms of how much mean squared error is increased. Replacing a strong predictor with noise will have a large effect on predictive ability. It may also happen that model prediction is slightly increased, which means that the original variable did not contribute to the prediction more than just a random noise. The largest improvement in prediction among all variables is used as a measure of prediction by error, and this amount is considered as Null improvement. To be of importance, a variable has to have importance larger than this Null. When variable importance is plotted for each of the variables, this Null value is usually marked to show which variables predict better than noise.

\section{Predictive accuracy}

We used the Receiver Operating Characteristic (ROC) curve as a tool to measure accuracy. A ROC curve is a plot of true positive rate versus false positive. The area under the curve (AUC) (a C-statistic) is equal to 0.5 if the model does not have any discriminating power and the area is equal to 1 when the model predicts the new outcomes perfectly well. A reliable and valid AUC estimate can be interpreted as the probability that the model will assign a higher score to a randomly chosen positive example than to a randomly chosen negative example.

\section{Results}

\section{Selected sample characteristics}

The sample sizes used in the analysis are summarized in Table 1 . The prevalence of having $\geq 3 \mathrm{ED}$ visits ranged from $4.0 \%$ in 2016 to $4.3 \%$ in 2017 . The distributions of demographic variables (age groups, gender, race/ethnicity, education, marital status, and insurance status) were relatively consistent across the 4 survey years (2015-2018).

\section{Predictive accuracy}

All models, including the model with all 46 variables as main effects, performed relatively similar to each other 
Table 1 Summary of sociodemographic variables and ED visits in the past 12 months among adults in the national sample of the NSDUH

\begin{tabular}{|c|c|c|c|c|c|c|c|c|}
\hline \multirow[t]{2}{*}{$\begin{array}{l}\text { Sample } \\
\text { Characteristic }\end{array}$} & \multicolumn{2}{|c|}{$\begin{array}{l}\text { Training } \\
\text { Dataset: } 2017\end{array}$} & \multicolumn{2}{|c|}{$\begin{array}{l}\text { Validation } \\
\text { Dataset: } 2018\end{array}$} & \multicolumn{2}{|c|}{$\begin{array}{l}\text { Additional Validation } \\
\text { Dataset: } 2015\end{array}$} & \multicolumn{2}{|c|}{$\begin{array}{l}\text { Additional Validation } \\
\text { Dataset: } 2016\end{array}$} \\
\hline & Count & Weighted \% & Count & Weighted \% & Count & Weighted \% & Count & Weighted \% \\
\hline \multicolumn{9}{|l|}{ AGE GROUP } \\
\hline $18-20$ & 4992 & 5.2 & 5125 & 5.2 & 5306 & 5.4 & 4912 & 5.2 \\
\hline $21-25$ & 8848 & 8.7 & 8512 & 8.5 & 9247 & 9.0 & 8748 & 9.0 \\
\hline $25-29$ & 3989 & 7.3 & 3868 & 7.1 & 4081 & 7.1 & 3948 & 7.2 \\
\hline $30-34$ & 4797 & 8.7 & 4926 & 9.0 & 5003 & 8.7 & 4803 & 8.7 \\
\hline $35-49$ & 11,214 & 24.7 & 11,688 & 24.6 & 11,169 & 24.9 & 11,361 & 24.8 \\
\hline $50-64$ & 4997 & 25.3 & 4938 & 25.0 & 5157 & 25.7 & 5241 & 25.5 \\
\hline 65 or Older & 3717 & 20.2 & 3969 & 20.7 & 3598 & 19.2 & 3612 & 19.7 \\
\hline \multicolumn{9}{|l|}{ GENDER } \\
\hline Male & 19,987 & 48.3 & 20,169 & 48.3 & 19,828 & 48.2 & 19,853 & 48.2 \\
\hline Female & 22,567 & 51.7 & 22,857 & 51.7 & 23,733 & 51.8 & 22,772 & 51.8 \\
\hline \multicolumn{9}{|l|}{ RACE/ETHNICITY } \\
\hline Non-Hispanic White & 25,870 & 63.8 & 25,834 & 63.4 & 26,025 & 64.7 & 25,969 & 64.4 \\
\hline Non-Hispanic Black & 5230 & 11.9 & 5400 & 11.9 & 5502 & 11.8 & 5474 & 11.8 \\
\hline Non-Hispanic Other & 4286 & 8.2 & 4327 & 8.4 & 4386 & 7.9 & 4110 & 8.1 \\
\hline Hispanic & 7168 & 16.1 & 7465 & 16.3 & 7648 & 15.6 & 7072 & 15.7 \\
\hline \multicolumn{9}{|l|}{ EDUCATION } \\
\hline Completed 6th grade or less & 632 & 2.0 & 678 & 2.3 & 798 & 2.4 & 735 & 2.5 \\
\hline Completed 7th - 9th grades & 1228 & 3.2 & 1219 & 3.1 & 1521 & 3.9 & 1216 & 3.3 \\
\hline Completed 10th -12 th grades & 3535 & 7.0 & 3540 & 6.9 & 3980 & 7.8 & 3538 & 7.0 \\
\hline Completed High School or Higher & 37,159 & 87.7 & 37,589 & 87.7 & 37,262 & 85.9 & 37,136 & 87.1 \\
\hline \multicolumn{9}{|l|}{ FAMILY INCOME } \\
\hline$<\$ 20,000$ & 8370 & 16.1 & 8118 & 15.7 & 9703 & 17.9 & 8939 & 17.0 \\
\hline$\$ 20,000-\$ 49,999$ & 13,321 & 29.5 & 13,139 & 29.4 & 14,015 & 30.0 & 13,493 & 30.0 \\
\hline$\$ 50,000-\$ 74,999$ & 6704 & 15.9 & 6672 & 15.5 & 6770 & 16.6 & 6543 & 15.9 \\
\hline$\geq \$ 75,000$ & 14,159 & 38.5 & 15,097 & 39.3 & 13,073 & 35.5 & 13,650 & 37.1 \\
\hline \multicolumn{9}{|l|}{ MARITAL STATUS } \\
\hline Married & 17,653 & 51.9 & 17,929 & 51.6 & 18,046 & 52.7 & 17,471 & 51.7 \\
\hline Never Married & 19,235 & 28.9 & 19,286 & 28.9 & 19,053 & 27.1 & 19,112 & 28.5 \\
\hline Divorced, Separated, or Widowed & 5666 & 19.2 & 5811 & 19.5 & 6462 & 20.2 & 6042 & 19.8 \\
\hline \multicolumn{9}{|l|}{ INSURANCE STATUS } \\
\hline Covered by Health Insurance & 37,790 & 90.5 & 38,097 & 90.1 & 38,104 & 89.4 & 37,755 & 90.5 \\
\hline Not Covered & 4764 & 9.5 & 4929 & 9.9 & 5457 & 10.6 & 4870 & 9.5 \\
\hline \multicolumn{9}{|l|}{ EMERGENCY DEPT. VISITS* } \\
\hline$<3$ Visits & 39,707 & 94.0 & 40,185 & 94.2 & 40,600 & 94.2 & 39,726 & 94.1 \\
\hline $3+$ Visits & 2013 & 4.2 & 1942 & 4.0 & 2127 & 4.0 & 2006 & 4.0 \\
\hline Missing data & 834 & 1.8 & 899 & 1.8 & 834 & 1.8 & 893 & 1.9 \\
\hline
\end{tabular}

*Missing data on ED visit were excluded from the analysis

when compared on predictive ability on the test set (Table 2). The stepwise regression model achieved AUC of 0.8 on training and validation datasets. The estimates of AUC were quite tight: bootstrap-based estimates of the standard deviation of AUCs for training and test sets was less than 0.01 . As expected, a single tree model predicted the worst, in part because it was designed to provide interpretable logical structure that would provide 
Table 2 Model fitting and predictive performance: $\geq 3$ emergency department visits/year

\begin{tabular}{lllll}
\hline Analysis sample & $\begin{array}{l}\text { Training } \\
\text { Dataset: 2017 }\end{array}$ & $\begin{array}{l}\text { Validation } \\
\text { Dataset: 2018 } \\
\text { Model }\end{array}$ & $\begin{array}{l}\text { Additional Validation } \\
\text { Dataset: } \mathbf{2 0 1 5} \\
\text { AUC }\end{array}$ & $\begin{array}{l}\text { Additional Validation } \\
\text { Dataset: } 2016 \\
\text { AUC }\end{array}$ \\
\hline All variables regression & 0.80 & 0.79 & 0.79 & 0.79 \\
LASSO & 0.80 & 0.79 & 0.79 & 0.79 \\
Stepwise regression & 0.80 & 0.79 & 0.79 & 0.79 \\
Single tree & 0.76 & 0.75 & 0.75 & 0.76 \\
Stepwise regression with complex interactions & 0.80 & 0.80 & 0.79 & 0.79 \\
Random forest & 0.88 & 0.79 & 0.79 & 0.79 \\
\hline
\end{tabular}

Note: All bootstrap-estimated standard deviations of the AUCs were $<0.01$. Because the model based on 2017 data has shown stability over the years, we have combined data from 2015 to 2018 to produce more stable estimates of odds ratios associated with multiple visits to the ED. In Table 3, we present the odds ratios and variable ranking from stepwise and forest models for 2015-2018 data

AUC Area under the curve, LASSO Least absolute shrinkage and selection operator, ED Emergency department

clustering of the sample according to the probability of recurrent ED visits.

Although regression models showed similar performance, they differed in the number of variables from 46 in the full model to 28 in the stepwise regression. These results suggest that the predictions and the factors associated with frequent visits to ED are quite robust and also that some variables are more important for prediction than others.

Because the prevalence of multiple visits was small, for the majority of individuals the probability of multiple visits remained $<0.5$ (i.e., a person was more likely not going to be a frequent ED user). However, for those who score over 0.20 ( 4 times over the mean of 0.05 ) the positive predictive value (PPV) was very high, over 0.98 , i.e., out of those who scored positive a chance that they are frequent ED user is 0.98 . For a small percentage of subjects who scored over 0.5 (more likely to be a frequent ED user than not) the PPV was over 0.999, which made the model a good screening test to identify extreme cases. A plot of a ROC curve (Fig. 1A) is another illustration of the balance between sensitivity and specificity in the best LASSO model, and in Fig. 1B we illustrate that the tail of the probability distributions contains mostly frequent ED users.

\section{Variable importance and consistency Tree variable}

A decision tree had a restriction of 400 observations per node and resulted in 14 nodes. This tree variable has a predictive AUC of 0.76 when predicting the 2018 data, which captures the essence of the interactions between the main variables.

Using the training data to produce the decision tree, the top interaction most related to multiple visits were between the self-rated health and having asthma. With respondents indicating fair/poor self-rated health combined with having asthma produced an estimate of $25 \%$ chance of multiple visits (more than five times the average). Those with fair/poor self-rated health with no asthma, but who were nervous all or most of the time, had 19\% chance of multiple visits. Those with fair/poor self-rated health with no asthma and who were not nervous most of the time, but who used illicit drugs were

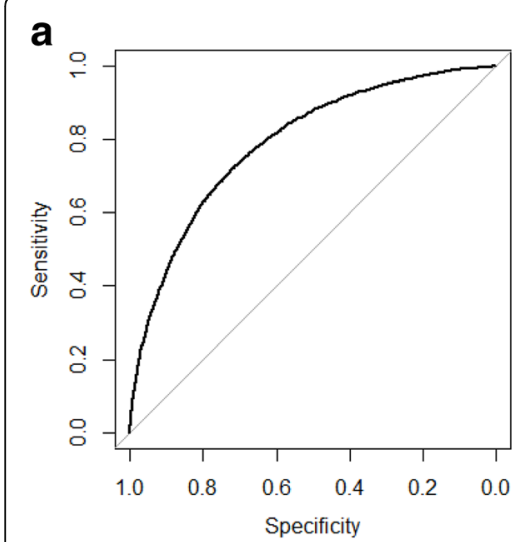

b

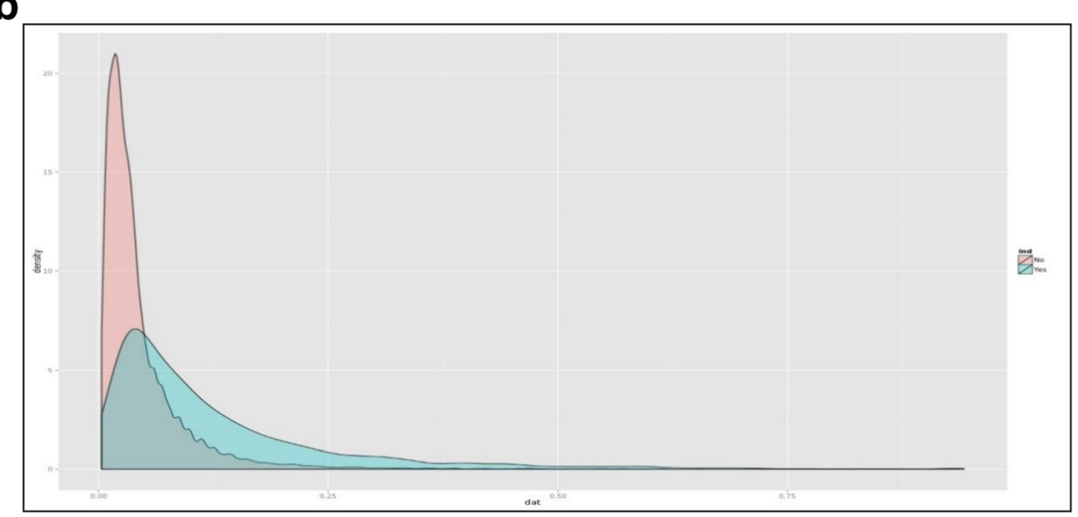

Fig. 1 a. ROC Curve Representing 0.79 Predictive Capability of the LASSO Regression Model on Validation Data from 2018. b. A Double Histogram Illustrating Positive Predictive Value (PPV) Depending on the Predicted Score. Most individuals with the predicted probability over 0.25 are frequent (3+ times per year) visitors to ED department 
the third largest category with $16 \%$ chance. Those with excellent/very good/good health, with income $<\$ 50,000$, being restless most or all the time, and being female had $12 \%$ chance of multiple visits. Nicotine dependence, and African American race were also important factors that modified a group with excellent/very good/good health, income $<\$ 50,000$ and not being restless most or all times. Among factors that decreased the chances of multiple visits were higher income and older age.

\section{Variable selection and importance}

Using 2015-2018 data, random forest-based variable importance was assessed. We ranked variables based on their permutation-based importance and compared to the variable list ranked by the formally calculated $p$ values in a stepwise regression. These nominal $p$-values would have been true p-values if the resulting regression model was a hypothesis-driven single analysis model. These quantities ignore multiple testing and the arbitrary selection of the training set, nevertheless, they are useful to evaluate the consistency of variables' ranks in different modeling approaches (Table 3).

Table 3 shows the variable importance according to the random forest for the top 25 variables according to the ranking of the $p$-values in the stepwise regression model. The top 25 variables according to the stepwise regression model covered the top 20 variables from the random forest model, except for education level (ranked 11 in the random forest model) and marital status (ranked 14 in the random forest model).

The highest-ranking variable in the 2015-2018 random forest model was fair/poor self-rated health followed by low income. Other strong predictors include gender, currently having asthma, restlessness, having a heart condition in the past year, race, age, ever having diabetes, feeling nervous or fidgety, education level, and nicotine dependence.

A similar list of variables appeared when we ranked variables in multiple regressions. In evaluating the model results on the combined 2015-2018 data, the largest effect sizes with OR $\geq 1.8$ estimated by LASSO were the following variables: fair/poor health $(\mathrm{OR}>2.6)$, lower income $(\mathrm{OR}>$ $2.5)$, having a heart condition in the past year $(\mathrm{OR}>2.4)$, HIV/AIDS (OR $>2.1$ ), being of younger age (OR $>2.0)$, being of African American race (OR $>1.8$ ), and having asthma $(\mathrm{OR}>1.8)$. Female gender, which appeared near the top of the list for in the other models, was also a predictive variable in the LASSO model with an OR of $>1.6$.

\section{Discussion}

We developed and validated predictive models in a large sample that estimated probabilities for an individual to have three or more ED visits within a year. For a national household sample, the models showed good predictive ability AUC reaching 0.8. The model appears to be stable across the studied years that suggests the stability of the estimates as well as a persistent behavior with respect to visiting an ED. The most influential variable that showed a strong and consistent effect across models was self-rated personal health fair/poor rating was the best predictor of multiple ED visits. This result is consistent with past clinical research [29]. By construct, the most influential variables impact sensitivity/ specificity at the overall population level. Such influential variables, however, can miss potential risk factors with high ORs but of low prevalence. If only few people have the given condition, their contribution to the population-level prediction can be small. We thus also considered the variables according to the size of their effects. One of such variables is cancer/malignancy of the larynx/windpipe or lung which produced an odds ratio of 2.6, but was not selected neither in the random forest nor in LASSO because of the relatively small sample. This effect became even more illustrative when we replicated the predictive process on data prior to 2015. For example, NSDUH datasets prior to 2015 contained variables on lung cancer and pancreatic diseases. When replicating the analysis on public use NSDUH 2014 data, the odds ratio estimates for lung cancer or pancreatic disease was large $(>4)$, however, because of a low prevalence (or small numbers of cases), their contribution to AUC improvement was small and they did not reach high statistical importance. At the same time, clinical importance could be high. That is, if a person happens to have a pancreatic disease, the chances of multiple visits to the ED could be highly increased.

Our findings are consistent with the ED use data from the Healthcare Cost and Utilization Project Nationwide ED sample, which shows that mood and anxiety disorders are among the leading contributors to ED visits and that younger adults and women have more ED visits than men and older adults [30]. The influential effect of nicotine dependence on multiple ED visits reaffirms a need to enhance smoking cessation, especially for African Americans and less-educated adults who are disproportionately affected by cigarette smoking $[31,32]$. Our results also indicate that African Americans/blacks and less-educated adults have a high likelihood of multiple ED visits within a year, which may be related to their comparatively high levels of disparities in healthcare use and poor health status $[33,34]$. The findings also highlight alcohol and illicit drug use as risk factors in multiple visits to ED.

These results have important implications for public health research. First, national healthcare reforms have shifted the healthcare model to a value-based model to address high costs and poor care concern in the U.S. [35]. Our findings indicate the need to identify effective care models to improve preventive services and 
Table 3 First 25 Predictors of $\geq 3$ emergency department visits in the past 12 months based on 2015-2018 data

\begin{tabular}{|c|c|c|c|c|}
\hline Variable Name & Reference Cell & $\begin{array}{l}\text { Odds Ratio in } \\
\text { a stepwise } \\
\text { regression }\end{array}$ & $\begin{array}{l}\text { Order in Stepwise regression } \\
\text { based on formal } p \text {-value of } \\
\text { first category occurrence }\end{array}$ & $\begin{array}{l}\text { Order in Random } \\
\text { Forest Model } \\
\text { Importance } \\
\end{array}$ \\
\hline Fair/Poor Health & $\begin{array}{l}\text { Excellent/Nery Good/Good Self- } \\
\text { Reported Heath }\end{array}$ & 2.63 & 1 & 1 \\
\hline Income $<\$ 25,000$ & Income $=>\$ 75,000$ & 2.53 & 2 & 2 \\
\hline Female Gender & Male & 1.62 & 9 & 3 \\
\hline Asthma (Current) & No Asthma & 1.87 & 8 & 4 \\
\hline $\begin{array}{l}\text { All/Most of the Time of the Time Feeling } \\
\text { Restless or Fidgety in Past Year }\end{array}$ & Some/Little/None of the Time & 1.47 & 16 & 5 \\
\hline 18-20 Years Old & Age 50-64 Years Old & 2.30 & 4 & 6 \\
\hline Black/African American Race & White Race & 1.91 & 7 & 7 \\
\hline Heart Condition in Past Year & No Heart Condition & 2.30 & 5 & 8 \\
\hline $\begin{array}{l}\text { All/Most of the Time of the Time Feeling } \\
\text { Nervous in Past Year }\end{array}$ & Some/Little/None of the Time & 1.28 & 26 & 9 \\
\hline $\begin{array}{l}\text { Education Level: 10th-12th grades } \\
\text { completed }\end{array}$ & 6 th grade or less completed & 1.43 & 17 & 10 \\
\hline Diabetes (Ever) & No & 1.62 & 10 & 11 \\
\hline Nicotine Dependence (Past Month) & No & 1.38 & 19 & 12 \\
\hline $\begin{array}{l}\text { Marital Status: Divorced, Separated, or } \\
\text { Widowed }\end{array}$ & Married & 1.16 & 33 & 13 \\
\hline COPD/Chronic Bronchitis (Ever) & No & 1.48 & 15 & 14 \\
\hline Tobacco Use (Past Year) & No & 1.29 & 23 & 15 \\
\hline Major Depressive Episode (Past Year) & No & 1.23 & 25 & 16 \\
\hline $\begin{array}{l}\text { No High Blood Pressure or Not Taking } \\
\text { Medication for High Blood Pressure }\end{array}$ & $\begin{array}{l}\text { Ever had High Blood Pressure or } \\
\text { Currently Taking Medication }\end{array}$ & 1.29 & 17 & 17 \\
\hline Illicit Drug Use (Past Year) & No & 1.33 & 21 & 18 \\
\hline Alcohol Use (Past Year) & No & 0.81 & 29 & 19 \\
\hline Illicit Drug Use Disorder (Past Year) & No & - & - & 20 \\
\hline Sexually Transmitted Disease (Past Year) & No & 1.58 & 11 & 21 \\
\hline Pain Reliever Misuse (Past Year) & No & 1.29 & 24 & 22 \\
\hline Had Insurance Coverage & No Coverage & 1.19 & 32 & 23 \\
\hline Pain Reliever Use Disorder (Past Year) & No & 1.49 & 13 & 24 \\
\hline $\begin{array}{l}\text { Population Density: Segment not in a } \\
\text { CBSA }\end{array}$ & Segment is in a CBSA & 1.25 & 28 & 25 \\
\hline
\end{tabular}

Note: In random forest, variable importance is evaluated with respect to the variable as a whole, rather than a specific category. In fact, the variable categories are randomly "scrambled." Thus, only one ranking value is issued for the variable. COPD Chronic obstructive pulmonary disease, CBSA Core Based Statistical Area - The variable/category is not present in the top category list or was not selected by the stepwise algorithm

continuity of care for less-educated adults, African Americans, and adults with tobacco use, anxiety, or depressive disorder. Second, the large national sample of the NSDUH provides the basis for testing robust validated models. Third, our findings have methodological implications. Variables with large effect sizes but low on predictive importance are indicative of the presence of low prevalence but high-risk clusters in the population. We thus distinguish between individualized and population-based predictions. We conducted post-hoc analyses in which we used the subsets of the pulled data to show that using a subset of the training set larger than 30,000 observations produced very similar population-based predictive models in terms of variable selection, effect size, and predictive performance to the original analysis that used about 60,000 observations as a training set. However, in order to identify small highrisk clusters large sample sizes provide necessary power and multiple years of the data could be combined to identify the specific effect sizes more precisely.

\section{Limitations and future work}

Predictive models based on nonclinical assessments from the NSDUH have predictive limitations. Although the list of medical conditions used in NSDUH is large, it is not complete and might miss some of the potentially 
important predictors. More research on large samples that includes a diverse set of measures is needed to improve predictive accuracy, especially at the identification of high-risk clusters.

Survey data from NSDUH contain analysis weights to produce unbiased estimates of population prevalence. Use of these weights may have the potential for development of better predictive models when the model parameters are unbiased. Although the use of analysis weights for regression methods is standard, methodology for the use of survey weights in tree-based models has not been well developed beyond initial assessment of sensitivity to weights [36]. We conducted sensitivity analyses to compare predictive performance of weighted and unweighted regression models and did not find any improvements in the AUC or the selection of the top predictors. LASSO models do not produce $p$-values, because standard errors are not very meaningful for strongly biased estimates such as arise from penalized estimation methods [37, 38]. Nevertheless, LASSO models are state of the art and have been broadly used to select the best subset of predictive variables [39].

\section{Conclusions}

A validated predictive model of frequent (three or more) ED visits within a year indicated that besides medical conditions, such as asthma, heart condition/disease, COPD, and diabetes, behavioral and mental health factors including lower self-rated health, being nervous or restless/fidgety, low income, low educational level, nicotine dependence, and depressive/anxiety signs or symptoms are among the most influential factors for multiple ED visits. These findings reveal the need to address behavioral and mental health contributors to ED visits and reinforce the importance of developing integrated care models in primary care settings to improve mental health for medically vulnerable patients. Although the list of medical conditions used in NSDUH is large, it is not complete and might miss some of the potentially important predictors. The remarkable consistency of predictive ability across the years assures that the results are stable and that the behavior of the subjects with respect to ED visits did not change much over the last several years. Presented modeling approach can be broadly applied to national and other large surveys.

\section{Supplementary Information}

The online version contains supplementary material available at https://doi. org/10.1186/s12913-021-06221-w.

Additional file 1: Table A1. Sociodemographic characteristics, substance use behaviors, mental health issues, and prevalence of ED visits in the past 12 months among adults in the national sample of the NSDUH.

\section{Acknowledgements}

Not applicable.

\section{Authors' contributions}

GB and LTW conceived the research questions, conducted the data analyses, and wrote the drafts and final manuscript. LKW has conducted data analysis, data interpretation and participated on writing of the manuscript. The author(s) read and approved the final manuscript.

\section{Funding}

This work was made possible by research grants from the U.S. National Institutes of Health (UG1DA040317 and R01MD007658 to Li-Tzy Wu). The National Institutes of Health had no role in the design and conduct of the study; collection, management, analysis, and interpretation of the data; or preparation, review, or approval of the manuscript. Its contents are solely the responsibility of the authors and do not necessarily represent the official views of the National Institutes of Health.

\section{Availability of data and materials}

The datasets used and analyzed are in public domain and are also available from the corresponding author on reasonable request.

\section{Declarations}

Ethics approval and consent to participate

The datasets from the National Survey on Drug Use and Health are deidentified and public available, which cannot be individually identifiable and therefore not involve human subjects.

Consent for publication

Not applicable.

\section{Competing interests}

The authors declare that they have no competing interests.

Received: 13 October 2020 Accepted: 28 February 2021

Published online: 25 March 2021

\section{References}

1. U.S. Goverment Accountabiliity Office. Hospital emergency departments: crowding continues to occur, and some patients wait longer than recommended time frames (GAO-09-347). Washington, DC: U.S. Goverment Accountabiliity Office; 2009.

2. Mullins PM, Pines JM. National ED crowding and hospital quality: results from the 2013 hospital compare data. Am J Emerg Med. 2014;32(6):634-9. https://doi.org/10.1016/j.ajem.2014.02.008.

3. Robert Wood Johnson Foundation. Quality Field Notes: Reducing inappropriate emergency department use requires coordination with primary care. In: Emergency Department Overuse, vol. 1: Robert Wood Johnson Foundation; 2013. https://www.rwj.org/en/library/research/2013/ 09/reducing-inappropriate-emergency-department.html. Last assessed on 03/10/2021

4. Cheung PT, Wiler JL, Lowe RA, Ginde AA. National study of barriers to timely primary care and emergency department utilization among Medicaid beneficiaries. Ann Emerg Med. 2012;60(1):4-10 e12. https://doi.org/10.1016/ j.annemergmed.2012.01.035.

5. Hunt KA, Weber EJ, Showstack JA, Colby DC, Callaham ML. Characteristics of frequent users of emergency departments. Ann Emerg Med. 2006;48(1):1-8. https://doi.org/10.1016/j.annemergmed.2005.12.030.

6. Sondergaard $\mathrm{H}$, Juul $\mathrm{S}$. Self-rated health and functioning in patients with chronic renal disease. Dan Med Bull. 2010;57(12):A4220.

7. Centers for Disease Control and Prevention. QuickStats: number of emergency department visits*()(dagger) for substance abuse or dependence( section sign) per 10,000 persons aged $>/=18$ years, by age group - United States, 2008-2009 and 2016-2017. MMWR Morb Mortal Wkly Rep. 2019;68(50):1171. https://doi.org/10.15585/mmwr.mm6850a7.

8. Santillanes G, Axeen S, Lam CN, Menchine M. National trends in mental health-related emergency department visits by children and adults, 20092015. Am J Emerg Med. 2019:38(12):2536-44. https://doi.org/10.1016/.a jem.2019.12.035. 
9. Shmueli G. To explain or to predict? Stat Sci. 2010;25(3):289-310. https://doi. org/10.1214/10-STS330.

10. Kuhn M, Johnson K. Applied predictive modeling. New York: SpringerVerlag; 2013. https://doi.org/10.1007/978-1-4614-6849-3.

11. Breiman L. Random forests. Mach Learn. 2001;45(1):5-32. https://doi.org/10.1 023/A:1010933404324

12. Sainani KL. Explanatory versus predictive modeling. PM R. 2014;6(9):841-4. https://doi.org/10.1016/.jpmrj.2014.08.941.

13. Hastie T, Tibshirani R, Friedman J. The elements of statistical learning: data mining, inference, and prediction. 2nd ed. New York: Springer-Verlag; 2009. https://doi.org/10.1007/978-0-387-84858-7.

14. Substance Abuse and Mental Health Services Administration. Key substance use and mental health indicators in the United States: results from the 2015 National Survey on Drug Use and Health (HHS Publication No. SMA 164984, NSDUH Series H-51). Rockville: Center for Behavioral Health Statistics and Quality, Substance Abuse and Mental Health Services Administration; 2016.

15. Substance Abuse and Mental Health Services Administration. Key substance use and mental health indicators in the United States: results from the 2016 National Survey on drug use and health (HHS publication no. SMA 17-5044, NSDUH series H-52). Rockville: Center for Behavioral Health Statistics and Quality, Substance Abuse and Mental Health Services Administration; 2017.

16. Substance Abuse and Mental Health Services Administration. Key substance use and mental health indicators in the United States: results from the 2017 National Survey on drug use and health. In. Rockville: Center for Behavioral Health Statistics and Quality, Substance Abuse and Mental Health Services Administration; 2018.

17. Substance Abuse and Mental Health Services Administration. Key substance use and mental health indicators in the United States: results from the 2018 National Survey on drug use and health. In. Rockville: Center for Behavioral Health Statistics and Quality, Substance Abuse and Mental Health Services Administration; 2019.

18. Wu LT, Swartz MS, Wu Z, Mannelli P, Yang C, Blazer DG. Alcohol and drug use disorders among adults in emergency department settings in the United States. Ann Emerg Med. 2012;60(2):172-80 e175. https://doi.org/10.1 016/j.annemergmed.2012.02.003.

19. Fleury MJ, Ngui AN, Bamvita JM, Grenier G, Caron J. Predictors of healthcare service utilization for mental health reasons. Int J Environ Res Public Health. 2014;11(10):10559-86. https://doi.org/10.3390/ijerph111010559.

20. Vitale $S$, van de Mheen D. Illicit drug use and injuries: a review of emergency room studies. Drug Alcohol Depend. 2006;82(1):1-9. https://doi. org/10.1016/j.drugalcdep.2005.08.017.

21. Shiffman S, Waters A, Hickcox M. The nicotine dependence syndrome scale: a multidimensional measure of nicotine dependence. Nicotine Tob Res. 2004;6(2):327-48. https://doi.org/10.1080/1462220042000202481.

22. Heatherton TF, Kozlowski LT, Frecker RC, Fagerstrom KO. The Fagerstrom test for nicotine dependence: a revision of the Fagerstrom tolerance questionnaire. Br J Addict. 1991;86(9):1119-27. https://doi.org/10.1111/j.13 60-0443.1991.tb01879.x.

23. Substance Abuse and Mental Health Services Administration. Results from the 2008 National Survey on drug use and health: national findings (NSDUH series H-36, HHS publication no. SMA 09-4434). Rockville: Substance Abuse and Mental Health Services Administration; 2009.

24. Kessler RC, Birnbaum H, Bromet E, Hwang I, Sampson N, Shahly V. Age differences in major depression: results from the National Comorbidity Survey Replication (NCS-R). Psychol Med. 2010;40(2):225-37. https://doi. org/10.1017/S0033291709990213.

25. Farkas J, Kosnik M, Flezar M, Suskovic S, Lainscak M. Self-rated health predicts acute exacerbations and hospitalizations in patients with COPD. Chest. 2010;138(2):323-30. https://doi.org/10.1378/chest.09-2459.

26. Smith PM, Glazier RH, Sibley LM. The predictors of self-rated health and the relationship between self-rated health and health service needs are similar across socioeconomic groups in Canada. J Clin Epidemiol. 2010;63(4):412-21. https://doi.org/10.1016/j.jclinepi.2009.08.015.

27. Tibshirani R. Regression shrinkage and selection via the Lasso. J R Stat Soc Ser B Methodol. 1996;58(1):267-88.

28. Lockhart R, Taylor J, Tibshirani RJ, Tibshirani R. A significance test for the Lasso. Ann Stat. 2014;42(2):413-68. https://doi.org/10.1214/13-AOS1175.
29. Hinami K, Smith J, Deamant CD, DuBeshter K, Trick WE. When do patientreported outcome measures inform readmission risk? J Hosp Med. 2015; 10(5):294-300. https://doi.org/10.1002/jhm.2366.

30. Owens PL, Barrett ML, Gibson TB, Andrews RM, Weinick RM, Mutter RL. Emergency department care in the United States: a profile of national data sources. Ann Emerg Med. 2010;56(2):150-65. https://doi.org/10.1016/j.a nnemergmed.2009.11.022.

31. Rostron BL, Chang CM, Pechacek TF. Estimation of cigarette smokingattributable morbidity in the United States. JAMA Intern Med. 2014;174(12): 1922-8. https://doi.org/10.1001/jamainternmed.2014.5219.

32. Xu X, Bishop EE, Kennedy SM, Simpson SA, Pechacek TF. Annual healthcare spending attributable to cigarette smoking: an update. Am J Prev Med. 2015:48(3):326-33. https://doi.org/10.1016/..amepre.2014.10.012

33. Cook BL, Liu Z, Lessios AS, Loder S, McGuire T. The costs and benefits of reducing racial-ethnic disparities in mental health care. Psychiatr Serv. 2015; 66(4):389-96. https://doi.org/10.1176/appi.ps.201400070.

34. Yang $Q$, Zhong $Y$, Ritchey $M$, Loustalot $F$, Hong $Y$, Merritt R, Bowman BA. Predicted 10-year risk of developing cardiovascular disease at the state level in the U.S. Am J Prev Med. 2015;48(1):58-69. https://doi.org/10.1016/j.a mepre.2014.09.014.

35. Conrad DA, Vaughn M, Grembowski D, Marcus-Smith M. Implementing valuebased payment reform: a conceptual framework and case examples. Med Care Res Rev. 2015;73(4):437-57. https://doi.org/10.1177/1077558715615774.

36. Toth D, Eltinge J. Building consistent regression trees from complex sample data. JASA. 2011;106(496):1626-36. https://doi.org/10.1198/jasa.2011.tm10383.

37. Kyung M, Gill J, Ghosh M, Casella G. Penalized regression, standard errors, and Bayesian lassos. Bayesian Anal. 2010;5(2):369-412. https://doi.org/1 0.1214/10-BA607.

38. Goeman J, Meijer R, Chaturvedi N. L1 and L2 penalized regression models. 2014. https://cran.r-project.org/web/packages/penalized/vignettes/penalized.pdf.

39. James $G$, Witten D, Hastie T, Tibshirani R. An introduction to statistical learning: with applications in R. Springer Texts in Statistics. Springer-Verlag New York; 2013. https://doi.org/10.1007/978-1-4614-7138-7.

\section{Publisher's Note}

Springer Nature remains neutral with regard to jurisdictional claims in published maps and institutional affiliations.
Ready to submit your research? Choose BMC and benefit from:
- fast, convenient online submission
- thorough peer review by experienced researchers in your field
- rapid publication on acceptance
- support for research data, including large and complex data types
- gold Open Access which fosters wider collaboration and increased citations
- maximum visibility for your research: over $100 \mathrm{M}$ website views per year
At BMC, research is always in progress.
Learn more biomedcentral.com/submissions 